Discussion

\title{
Sustainable Product-Service Systems and Circular Economies
}

\author{
Ricardo J Hernandez
}

DILAB School of Engineering and School of Design, Pontificia Universidad Católica de Chile, Santiago 8331150, Chile; rhernandep@uc.cl; Tel.: +56-9-8687-5677

Received: 18 August 2019; Accepted: 24 September 2019; Published: 29 September 2019

\begin{abstract}
Sustainable product-service systems (PSSs) have proven to be a very good alternative for developing new business models and transforming traditional offers into sustainable ones. Environmental, social and economic benefits support the idea of developing this type of system. However, there are identified challenges that have stopped the expansion of the concept into the market. The framework that explains the principles and building blocks of a circular economy according to the Ellen MacArthur Foundation can be an interesting lens to analyse the challenges companies faced when they wanted to implement a sustainable PSS. This framework is particularly useful to understand the internal and external forces companies are dealing with in a transformation from traditional business models to ones like sustainable PSSs that need special conditions of operation. Design for sustainability as an area of study will shift in the coming years to focus its attention on the requirements of circular economics as the paradigm of production and consumption. Sustainable products, services and systems will be developed according to the conditions established by those circular conditions.
\end{abstract}

Keywords: sustainability; product-service systems; design process; circular economies

\section{Introduction}

The idea of product-service systems (PSSs) as integrated solutions of products and services that have the potential to fulfil final users' needs in a sustainable manner has been around for more than a decade [1]. However, the adoption of the concept in industry is still limited [2-4], and examples of this business approach in the market, especially in Business-to-Customer (B2C) operations, are scarce [3-6]. In this context, "sustainable manner" refers to "the principle of ensuring that our actions today do not limit the range of economic, social and environmental options open to future generations" [7]. This principle expressed first in the Brundtland report [8] has been developed further by multiple authors. The contribution of a PSS to this principle is associated with the recognised necessity to find models of production and consumption around a sustainable agenda "focusing on economic prosperity, environmental quality and ... social justice" [7]. This idea of a triple bottom line developed by Elkington is how "sustainable" is understood in this paper, implying that sustainable PSSs are systems of products and services that, acting together, favour the creation of economic, environmental and social value in a conscious and balanced way.

Regarding the low rate of adoption of sustainable PSSs in industry [3,9], Tukker and Tischner [10] affirm that from a business perspective a shift to a PSS, as with any other business movement, has to be studied and carefully managed because it is possible to lose competitive advantages and not achieve the expected benefits. Meanwhile, Cook et al. [2] found in their research that UK manufacturers did not perceive any real incentives to such a change as they did not recognise many examples of PSSs in the market with significant results relating to the triple bottom line. Another reason identified by Beuren et al. [11] is that the majority of the studies and literature in the field has been highly theoretical 
and that more empirical research is needed. This lack of empirical evidence is crucial especially for small business with little space to try unproved alternatives. In this context and despite the increasing number of academic papers in recent years in this field [6], the design of sustainable PSSs is still a young area of study and there are only few studies addressing specifically the support needed in the early stages of the design process for this type of system. This paper presents a reflexion about the development of sustainable PSSs, taking data from a research study done a few years ago and analysing those results using, as a framework, the principles and building blocks of a circular economy according to the Ellen MacArthur Foundation [12]. This paper does not provide a new framework to design sustainable PSSs; instead it proposes a discussion about how the work done by the Ellen MacArthur Foundation on circular economies can be used as a model to help companies to understand and develop the competencies they need to design and develop a sustainable PSS. In this discussion, the main objective is to highlight the importance of generating industrial and external conditions to allow those companies to develop a sustainable PSS even before internal capabilities are considered. Despite the fact that the relationship between PSSs and circular economies has already been addressed [6,13], the focus has been on understanding how sustainable PSSs can contribute to producing circularity [14]. The focus here, however, is actually the opposite- how the elements already developed to deploy circular economies can help companies to understand and develop the business environment and competencies they require to design and develop a sustainable PSS.

In the following sections, the paper presents the context in which the reflexion was developed. Section 2 comprises a literature review, Section 3 presents the main conclusions drawn from a research study carried out with a group of 16 SMEs, Section 4 presents the relationship between sustainable PSSs and circular economies and finally, in Section 5, a discussion is presented about the possible contribution elements from the design and development of circular economies that could benefit the development of sustainable PSSs.

\section{Literature Review}

One of the first formal definitions of a product-service system (PSS) was presented by Goedkoop et al. [15] as "a marketable set of products and services capable of jointly fulfilling a users' need". After this first attempt to formalise the PSS concept, other authors have made important additions to it, presenting PSS as an "innovation strategy" [1] with a special emphasis on the power that PSSs have to shift the focus of a business from producing and selling physical goods to developing and offering services. Mont [16] and Tukker [17], respectively, mention that products and services are not enough to fulfil the user's needs; PSSs require infrastructure and networks supporting those products and services to create and deliver the value from the system. Finally, there is also recognition that PSSs can have a lower environmental impact than traditional offers [16], and in some cases offer social benefits [18].

This potential of PSSs to have an improved environmental performance and to favour social responsibility while also creating economic value has also been mentioned by other authors [19-22]. However, the idea that PSSs are more sustainable than traditional business models, understanding sustainable as the potential of create economic, environmental and social value, is not a default feature in this type of systems [10]. It is acknowledged that PSSs can be innovative and sustainable solutions but the systems have to be designed with that purpose [14,21].

\subsection{Sustainable Product-Service Systems (PSSs)}

The potential sustainability of a PSS relies on the integrated design of all the elements in the system to fulfil a function [16]. Due to this integration, it is possible that the economic interests of the stakeholders, as partners in the development of the systems, converge thereby encouraging the optimisation of the whole system [1]. It is from this optimisation that environmental and social benefits arise because one function can be fulfilled with many different system configurations [15]. It is that level of freedom that allows the stakeholders in the system to find efficient, innovative and 
sustainable solutions [1,14]. However, this argument implies that not all PSSs may have the potential to be sustainable solutions. Between the different types of PSS, user-oriented and result-oriented systems with a focus on the fulfilment of functions are the ones with the greatest potential to be sustainable [17]. According to Tukker and Tischner [10,23], this sustainable potential is partly associated with the capacity to fulfil needs with systems based on services rather than on products, as has been the tradition in many industries.

Systems with this potential to be sustainable solutions can be found in the mobility industry, for example, with car-sharing offerings like car2go [4,24]. This PSS provides an infrastructure comprising vehicles, stations and a dedicated information system allowing the users to access the network of vehicles distributed across a city and control their usage. The system satisfies the need of mobility (travelling from A to B) that can be useful for different types of customers including students, part-time workers, visitors and long-distance commuters. In the service provided by the system, the type of car offered, the fuel used by the cars or even the exact position of the stations are in many cases inconsequential to the users. It means that the provider of the system can choose to operate, for example, small vehicles with a low fuel consumption and in general with a better environmental performance than traditional rental cars. This better environmental performance depends, for example, on the type of energy used for the systems. If the energy cars use is clean and safe and made from renewable sources, the system as a whole can have a better performance than traditional offers, considering also the scale of the operations. A system like car2go can have a sustainable performance if using the system means a significant reduction in the production and sale of traditional cars, which are in many cases underused. This level of freedom to design the systems can result in more sustainable integrated solutions in comparison with other traditional forms satisfying the same need [3]. Other cases in the set of very limited examples of sustainable PSSs actually in operation can be found in document and printing services [25] and chemical and resource management services [5]. It is important to mention that not all PSSs are sustainable or beneficial for the environment by default; they have to be designed and deployed with the objective to be sustainable in mind, thereby avoiding possible rebound effects [3].

\subsection{Benefits from Sustainable PSSs}

Product-service systems (PSSs) designed to satisfy customers by innovative means, optimising the use of resources in the system and creating value in the three dimensions of the triple bottom line - environment, society and economy — can be considered as sustainable PSSs [26]. In this case, there are different kinds of benefits PSSs can generate. In economic terms, sustainable PSSs can create differentiation, have flexible offers, encourage innovation, increase customers' loyalty, put businesses in a better strategic position [23,27], increase revenues for providers and offer better value propositions for customers [28]. In terms of social benefits, sustainable PSSs can create awareness of relationships between stakeholders, contribute to building collaborative networks, make markets more diverse while benefiting the customers and, finally, they can enable people to access services, through communal and rental systems, previously inaccessible due to costs or physical restrictions [18,20].

However, more benefits from sustainable PSSs are recognised in the environmental dimension. Several authors have highlighted diverse environmental benefits achievable through servitisation and virtualisation in a PSS. Those benefits arise from a reduction in the use of raw materials, a decrease in energy consumption, a reduction or an elimination of hazardous materials, a reduction in the volume of products produced, less generation of waste and less dependency on material offers to satisfy customers' needs $[2,10,16,29]$. Additionally, we observe a more efficient use of products, longer product life cycles, closed material flows and more efficient scenarios of final disposal due to the increase of responsibility in the producers $[16,30]$. 


\subsection{Challenges in the Design of Sustainable PSSs}

Despite the potential benefits in terms of environmental and social performance and the economic attractiveness, sustainable PSSs have not been widely adopted by industry [9]. Among the diverse challenges that can discourage businesses from designing and implementing a sustainable PSS, it is possible to distinguish two groups. First, there are challenges specifically linked to the system's design and, second, there are those related to the system's operation [26]. Concerning the first group, Creusen [31] mentions that one of the main difficulties in designing sustainable PSSs is achieving products and services that together can create value and be consistent with the aim of the system. The complexity in the design of the elements of the PSS implies, for example, allowing the participation of other stakeholders in the design process, sharing information and control to achieve the optimisation of the system and finding a way to integrate economic, environmental and social aspects in the design of the system [10,31]. Concepts such as product life cycle, closed loops, intangible value, reuse, leasing and sharing become important in the design of sustainable PSSs [18,27]. In many cases, businesses do not have the knowledge to understand some of those concepts or the capacity to integrate them into their design process, and consequently there is a natural resistance against developing a PSS [2,26]. Within this group of challenges associated with the design of the systems, there are also the difficulties related to the use of tools available to support the design of sustainable PSSs.

The second type of challenges that can discourage businesses from designing and implementing sustainable PSSs is associated with the operation of the systems. First, PSSs put usually more responsibility on producers, who in many cases retain the ownership of the system's products and infrastructure. Producers then become responsible for ensuring the correct operation of those products over long periods, guaranteeing also their efficient and sustainable final disposal. This challenge associated with the change in the ownership of physical elements in the systems is linked to the transformation of roles. In sustainable PSSs, mainly user- and result-oriented ones, businesses and clients make a shift from producers and consumers of products, respectively, to being providers and users of a function. The attachment to physical products causes resistance on both sides and a significant effort is needed to break traditional relationships [10,27]. Another challenge associated with the operation of the system is the fact that sustainable PSSs are usually an unknown concept for a traditional business and it requires collaboration and strong links between different actors to develop and deliver the promised value. Efficient communication between many others represents one of the competencies required by businesses collaborating to operate a sustainable PSS. Finally, businesses have similar doubts to the ones consumers may have about the operation of a PSS, such as difficulties in understanding the costing and pricing structure in these systems [32] or the risk perception of having to engage in costly implementations, or in the case of consumers, doubts about costly contracts without being sure of the benefits [33]. The implementation and operation of a sustainable PSS can generate a lot of uncertainty that stops businesses from trying to put the concept into practice.

As the literature review indicates, PSSs have the potential to be innovative and sustainable solutions, but they are not widely adopted in industry. Some of the reasons for this are linked to the challenges associated with designing the systems, while others are related to the challenges of operating the systems.

\section{Sustainable PSSs in Small and Medium Enterprises (SMEs)}

Taking into account the challenges related to developing a sustainable product-service system (PSS) identified in the literature, a research study was carried out in 2012. That research had as its main objective to explore the possibility of a group of small and medium enterprises (SMEs) making a transformation from traditional offers to sustainable PSSs. The investigation was done as part of a larger exploratory research project about the design of sustainable PSSs involving small businesses, a case study with a group of 16 Colombian manufacturing SMEs all belonging to the footwear and leather manufacturing industry [26]. That study was developed as a single case study with multiple units of analysis following the recommendations of [31,34] and [35]. The case study's aim was to identify 
opportunities and barriers of a potential transformation in the companies from product-oriented offers to sustainable PSSs, and also to corroborate the challenges to design sustainable PSSs found in the literature review, as well as to identify new ones.

Each of the 16 SMEs involved in the case study was approached to carry out a semi-structured interview with the owner or the general manager. The interviews were transcribed and then coded following a thematic analysis. The initial coding was done using a template developed from the insights gained in the literature review and the interviewing process. The template was refined in three iterations following the recommendations given by Robson, Gibbs and King [34,36,37], respectively, and using the first four transcriptions until a final version of the template was produced. After the transcriptions were coded, a clustering process was carried out to put together all the common pieces. This was an analytical process partly done through Nvivo [26] and partly done manually, looking to make sense of the information collected in relation to the aim of the case study.

The clustering process resulted in six major themes gathering fifty-eight subthemes. The six major themes that emerged from this analysis were as follows: the role of design in the SMEs, sustainability in SMEs, the use of technology in the design process, the business environment, the relationship with stakeholders, and the business tradition and dynamic, all in relation to the design of sustainable PSSs. Different results emerged from this coding and clustering process and from the analysis of the themes built during this process. The results of this study were published by Hernandez et al. [38,39] and by Hernandez [26].

\section{Insights from the Case Study}

Following the methodology described in the previous section, the case study with the 16 Colombian SMEs from the footwear and leather industry was carried out. Among the multiple results obtained from the analysis performed on the information collected in this case study, there was a set of important conclusions about the capacity of those SMEs to eventually develop a sustainable PSS:

- The SMEs did not know the PSS concept, neither the implications of having one in relation to the environmental, social and economic benefits they could achieve.

- There was a lack of financial resources among the SMEs to develop and implement a new business configuration and offer. This financial issue has been recognised before as an important obstacle to developing sustainable PSSs [32].

- All the SMEs had product-oriented offers. None of them provided services to their final customers, but a few of them had changed specific physical tasks in their design and production processes to virtual ones, like the evaluation of prototypes.

- The SMEs recognised the importance of design and they were open to investing in design and to changing their current situation where design was an external capability that they had to pay for and for which they had very little control over the knowledge produced in the process.

- In general, there was a lack of knowledge and awareness about sustainability and possible strategies they could implement to develop sustainable operations and products using design. Only a couple of companies mentioned something regarding environmental pressure in their industry, without mentioning any plan or actions taken to face this challenge.

- There was also a significant ignorance about the importance of having a well-defined business strategy and the connection between a business strategy and the opportunities to transform their operations towards a sustainable PSS.

- The conditions in the industry, mainly linked to payment delays, formal and informal competence, taxes and distrust among actors in the supply and production chain, were also part of the difficult scenario these SMEs faced when thinking about improving their offers and making a transformation to sustainable PSSs.

These conclusions in general showed the very precarious situation these SMEs were in when planning to make a potential transformation to a sustainable PSS. Most of the points highlighted in 
the case study revealed a lack of internal capabilities in this group of SMEs to develop a sustainable offer using the PSS concept. This lack of internal capabilities, especially the absence of design capacity, was one of the major issues considered at that moment in preventing the SMEs from making a change towards sustainable PSSs. In the majority of the SMEs, design was done by external actors specialised in making the patterns needed for the manufacturing process. In general, there were very few innovations among these SMEs. The normal process was that the SMEs searched models of shoes they were interested in, on the Internet or in fashion magazines, and then with the picture they asked those external actors to transform the photos into patterns to make the shoes. Only one company reported carrying out a design process in house, starting from sketches and rough ideas until they developed internally the patterns for manufacturing. This fragmented and external design process was considered at the time an important obstacle for these SMEs to developing more sophisticated and sustainable offers. This result confirms some of the conclusions drawn by Baines et al. [25].

Among the issues revealed in this study, external conditions were partially evaluated; the main conclusion was that the SMEs were working under difficult agreements with clients and suppliers, and that the industry in general was facing significant challenges like smuggling, unfair competition and tax problems. Trust among actors in the supply chain was also considered among these external conditions as one big obstacle to developing sustainable PSSs. Trust issues have been identified before as problematic in the development of PSSs [40]. Despite this diagnostic, little was done about the external conditions and the analysis was focused on the internal capabilities of the SMEs.

Today, seven years later from the time when this case study was done, it is very interesting to go back to the transcriptions and to analyse the data with the framework provided by the knowledge and information we have now about circular economies [12]. It is especially interesting to evaluate the conclusions of this case study considering a change of paradigm from lineal production and consumption to circular economies. At that time, such a change was seen as very far from happening; however, after years have passed, good signs have hit the market and the industry. Currently, sustainable PSSs are recognised as one of the business models that fits well the principles and characteristics of a circular economy [6]. The results of the case study are still valid today, and reviewing the data again reveals that the initial conclusions were consistent with the situation of the companies and also with the conditions other authors found important to developing a PSS, such as being competent in design [25]. However, the recommendations presented to those SMEs today would be probably different in terms of the order in which they should take actions to develop a sustainable PSS. While improving their internal capabilities in design or their knowledge about sustainability and life cycle [22] are still important actions, I think today, from a circular economy perspective, the focus should be first on providing the industrial conditions needed to develop sustainable PSSs. Conditions like stronger and more transparent relationships among the actors in the supply chain [6], design policies and taxes that facilitate the provision of services [3] and networks of support to help the SMEs to understand the PSS concept and connect them to the final customers are just a few of the actions that should be taken at the beginning of a transformation towards a sustainable PSS.

\section{Sustainable PSSs and Circular Economies}

The circular economy is a concept developed during the last decades, but which has gained great importance especially in the last ten years due mainly to the work of the Ellen MacArthur Foundation. In 2012, the Ellen MacArthur Foundation presented the concept as follows:

The circular economy refers to an industrial economy that is restorative by intention; aims to rely on renewable energy; minimizes tracks, and eliminates the use of toxic chemicals; and eradicates waste through careful design. The concept of the circular economy is grounded in the study of non-linear systems, particularly living ones. A major consequence of taking insights from living systems is the notion of optimizing systems rather than components, which can also be referred to as 'design to fit'. It involves a careful management of material flows, which, in the circular economy, are of two types as described by McDonough and 
Braungart [cradle-to-cradle]: biological nutrients, designed to re-enter the biosphere safely and build natural capital, and technical nutrients, which are designed to circulate at high quality without entering the biosphere. [12]

Behind this concept is the recognition that the lineal model of "Take, Make, Dispose" has brought significant negative impacts over the environment and large social inequities. Circular economy is not a concept that emerged out from the blue; it is instead the joined effort of different schools of thought around the globe. The concept includes insights from regenerative design, performance economy, cradle-to-cradle, industrial ecology and biomimicry, among many others [12].

The importance of the circular economies concept with respect to other approximations to make the changes we need as a society to become sustainable and ensure our survival and that of the planet is that it unifies the need for change, with the systemic level required, and the tools that can produce that change. From the beginning, large corporations like Google, Philips, Renault and Unilever were invited as global partners in the journey traced by the Ellen MacArthur Foundation [12]. With time, more companies, universities, consultancies and philanthropic organizations have joined efforts towards the goal proposed to transform our production and consumption systems into circular ones. The concept has even infiltrated governmental agendas and it is today discussed in important scenarios around the world alongside themes like global warming and the objectives of sustainable development from the United Nations. In general, important environmental and social benefits are recognised in a circular economy [41] and it is probably the most promising concept to achieve a sustainable way of living [42].

In relation to the case study with the Colombian small and medium enterprises (SMEs), it is interesting to analyse the conclusions drawn from the study against the principles and pillars of the circular economy. It is interesting because sustainable PSSs are the type of business model transformations that the circular economy is asking for, as one of the four building blocks mentioned by the Ellen MacArthur Foundation [12]. Then, the main question in this reflexion is what has to be done first to motivate the transformation of current product-oriented businesses to ones that can operate in a circular economy. The focus should be on the internal capabilities to transform products into services and systems, or the effort should be on developing first the external conditions to ensure the operations of this type of sustainable system.

In the descriptions given by the Ellen MacArthur Foundation, the circular economy has four main building blocks-skills in circular product design and production, new business models, skills in building reverse cycles and cascades, and enabling factors to improve cross-cycle and cross-sector performance. Additionally, it relies on a few principles defined as follows: design out waste, build resilience through diversity, rely on energy from renewable sources, think in "systems" and waste is food [12]. In these terms, the Ellen MacArthur Foundation presents examples of concrete actions to be taken in parallel in the four building blocks to transform industries like mobile phones, light commercial vehicles and washing machines [12].

However, according to the experience gained during the case study with the 16 SMEs and going back to the data, the focus was placed on developing actions in the four building blocks described by the Ellen MacArthur Foundation in parallel, whereas the external and industrial conditions should have been addressed first. At that time, the conclusions and recommendations to the SMEs were mainly focused on the internal capabilities the companies should have to design products and services that could integrate sustainable PSSs. Even if some conclusions concerned the difficult conditions those companies were experiencing with their suppliers and clients, there was no integration between the objective of developing sustainable PSSs and the industrial requirements needed to achieve circular production and consumption.

In terms of the four building blocks needed to develop a circular economy, the recommendations made to the SMEs followed the logic shown in Figure 1, giving special attention to the first three blocks and proposing parallel actions for the four of them. Even if at that time the final recommendations to the 16 SMEs were not expressed in this way, it is possible today to see how looking at the research outcomes through the lens of the circular economy helps greatly in understanding the situation of those 
companies. It also helps to understand the chances they actually have today in making a transformation towards sustainable PSSs embedded within circular economies. In contrast, the approach that I suggest here puts an initial special attention on the block linked to the external and industrial conditions needed to develop circularity and then on the internal capabilities of the SMEs to design and develop products, services and systems in the form of sustainable PSSs (see Figure 2).

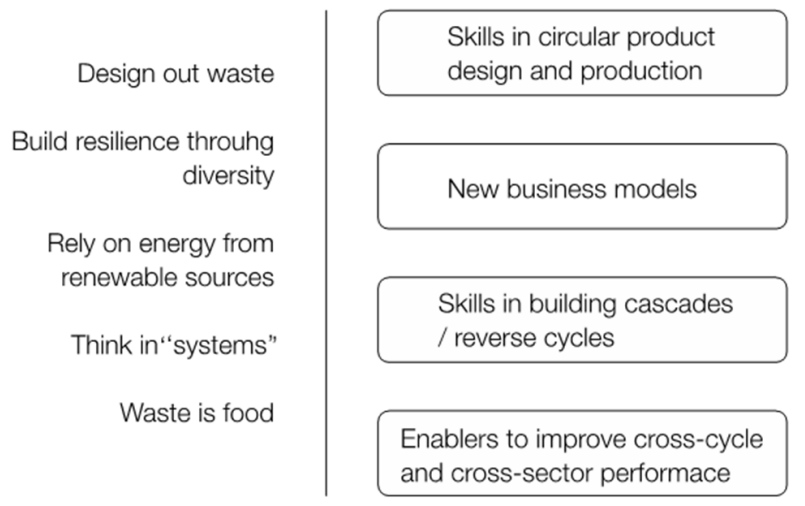

Actions

Figure 1. Actions taken in parallel in the four building blocks [12].
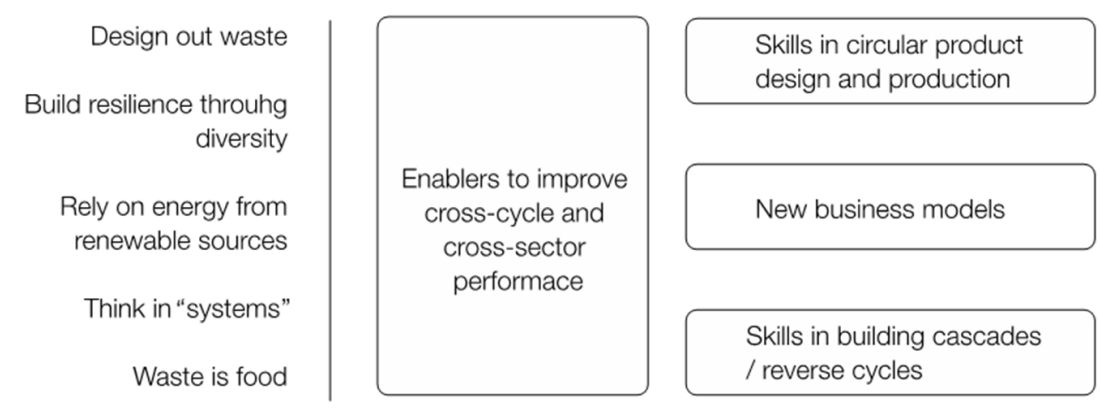

Actions

Figure 2. Actions taken first in the block linked to external and industrial conditions [12].

It can be very different for other industrial sectors or for companies that are not making a transition to sustainable PSSs from traditional offers. Perhaps, for new business developments, it is possible to take actions in the four building blocks at the same time, but my experience working with companies that are product-oriented and want to make a transformation to sustainable PSSs is that the external and industrial conditions should be addressed first and the actions in the other three blocks should be taken later. This conclusion is backed up by previous research where relation management skills are identified as a key factor in the development of sustainable PSSs, even over design capabilities [25]. Relation management should include a deeper knowledge and understanding of users [43].

\section{Discussion}

After analysing the reasons for the lack of examples of sustainable product-service systems (PSSs) in the market [2-4], the conclusions drawn from the case study carried out with the group of 16 SMEs and also the conditions required to achieve a transformation from lineal production and consumption systems to circular economies, I believe the emphasis should be first put on generating the external conditions that sustainable PSSs need to operate, and then on developing the internal capabilities that companies need to design and develop products and services integrated into sustainable PSSs. As the Ellen MacArthur Foundation suggests, there should be actions related to providing those external conditions, such as improving collaboration, rethinking incentives for producers and customers, 
providing international environmental rules and giving access to financial resources [12], in order to provide the right business environment for companies that want to develop a sustainable business model oriented toward achieving circularity.

In this context, I think sustainable PSSs require specific conditions before they can be established and operated successfully. The principles and building blocks of the circular economy framework proposed by the Ellen MacArthur Foundation can provide these conditions. The proposal then is to develop that framework in the order presented in Figure 2, providing first the "enablers to improve cross-cycle and cross-sector performance" and then to develop actions in the other three blocks. In fact, Tukker [6] recognises that companies in industries where the competitive advantage is on product manufacturing and design may lose rather than gain a better strategic proposition. In this context, before companies make a transformation of their internal capabilities and operation, actions should be oriented toward changing the business environment where those companies will operate once the transformation has been done. Providing a better business environment could help users to accept an offer where they do not have the ownership of the products due to the formalisation and institutionalisation of the system. Providing a well-structured business environment can help to foster confidence in the users and the companies before they commit to large and sometimes expensive transformations.

It is interesting that, for this case and according to the data collected, the recommendation is actually to start the intervention, taking actions first in the block linked to the external and industrial conditions. In other situations, the case may be that the emphasis should be placed on one of the other three blocks first and then on the others. In one way, it is interesting to use the building blocks proposed by the Ellen MacArthur Foundation in a flexible manner to customise the development of the conditions required to develop a circular economy, which in my view are almost the same conditions required to develop a successful sustainable PSS. In another way, there is a virtuous cycle between developing the right conditions to develop a sustainable PSS and the emergence of circularity. The point in this discussion is that since sustainable PSSs can be used as the starting point to develop a circular economy, the elements of a circular economy can, in the opposite way, be used to develop sustainable PSSs. Figure 3 shows the essence of the proposal organising the principles and building blocks of a circular economy presented by the Ellen MacArthur Foundation in a different configuration, conserving the actions linked to the industrial and external conditions first in the process.

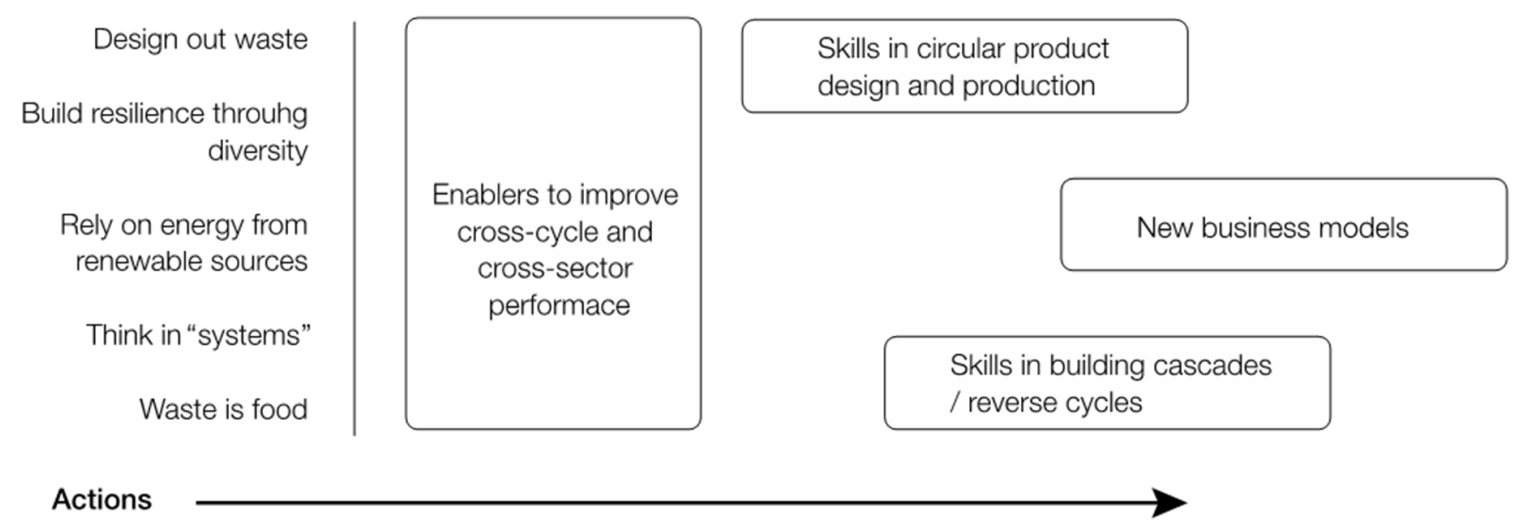

Figure 3. Alternative configurations of actions to develop sustainable PSSs based on the elements to build circular economies [12].

Finally, with respect to design for sustainability as an area of study, the future will be strongly linked to the conditions and characteristics of circular economies. We are living a change of paradigm from lineal production and consumption models towards circular economies where producers and consumers will have to know about things such as closed material loops, reuse, remanufacturing and recycling and even about biological cycles. Every effort in developing sustainable products, services and business models will have to be framed by the requirements of that change of paradigm. Concepts 
like eco-design or eco-efficiency will be used in the context of transformations from lineal to circular production and consumption, and new businesses will probably jump over those concepts to go straight to talk in terms of the skills required to develop circular systems and, in that context, to talk about sustainable PSSs.

Funding: This research was originally funded by Colciencias and COLFUTURO as part of the doctoral studies of the author.

Acknowledgments: The author wishes to thank Professor Tracy Bhamra at Loughborough University for the support and help during his doctoral studies and throughout the following years.

Conflicts of Interest: The author declares no conflict of interest.

\section{References}

1. Manzini, E.; Vezzoli, C. A strategic design approach to develop sustainable product service systems: Examples taken from the 'environmentally friendly innovation' Italian prize. J. Clean. Prod. 2003, 11, 851-857. [CrossRef]

2. Cook, M.; Bhamra, T.; Lemon, M. The transfer and application of Product Service Systems: From academia to UK manufacturing firms. J. Clean. Prod. 2006, 14, 1455-1465. [CrossRef]

3. Vezzoli, C.; Ceschin, F.; Diehl, J.C.; Kohtala, C. New design challenges to widely implement 'sustainable product-service systems. J. Clean. Prod. 2015, 97, 1-12. [CrossRef]

4. Cherubini, S.; Iasevoli, G.; Michelini, L. Product-service systems in the electric car industry: Critical success factors in marketing. J. Clean. Prod. 2015, 97, 40-49. [CrossRef]

5. Anttonen, M. Greening from the front to the back door? A typology of chemical and resource management services. Bus. Strat. Environ. 2010, 19, 199-215. [CrossRef]

6. Tukker, A. Product services for a resource-efficient and circular economy-A review. J. Clean. Prod. 2015, 97, 76-91. [CrossRef]

7. Elkington, J. Cannibals with Forks; Capstone Publishing Limited: Oxford, UK, 1997.

8. WCED. Our Common Future; Oxford University Press: Oxford, UK, 1987.

9. Vezzoli, C.; Ceschin, F.; Diehl, J.C.; Kohtala, C. Why have 'sustainable product-service systems' not been widely implemented? J. Clean. Prod. 2012, 35, 288-290. [CrossRef]

10. Tukker, A.; Tischner, U. New business for old Europe: Product-service development. In Competitiveness and Sustainability; Greenleaf: Sheffield, UK, 2006.

11. Beuren, F.H.; Ferreira, M.G.G.; Miguel, P.A.C. Product-service systems: A literature review on integrated products and services. J. Clean. Prod. 2013, 47, 222-231. [CrossRef]

12. Ellen MacArthur Foundation. Towards the Circular Economy: Economic and Business Rationale for an Accelerated Transition; Ellen MacArthur Foundation: Cowes, UK, 2012.

13. Matschewsky, J. Unintended circularity?-Assessing a product-service system for its potential contribution to a circular economy. Sustainability 2019, 11, 2725. [CrossRef]

14. Zeeuw van der Laan, A.; Aurisicchio, M. Designing product-service systems to close resource loops: Circular design guidelines. Procedia CIRP 2019, 80, 631-636. [CrossRef]

15. Goedkoop, M.; van Halen, C.; Riele, H.T.; Rommens, P. Products Service Systems, Ecological and Economic Basics; Dutch Ministries of Environment (VROM) and Economic Affairs (EZ): Hague, The Netherlands, 1999.

16. Mont, O. Clarifying the concept of product-service system. J. Clean. Prod. 2002, 10, 237-245. [CrossRef]

17. Tukker, A. Eight types of product-service system: Eight ways to sustainability? Experiences from SusProNet. Bus. Strat. Environ. 2004, 13, 246-260. [CrossRef]

18. Ness, D. Sustainable product service systems: Potential to deliver business and social benefits with less resource use. In Greening the Business and Making Environment a Business Opportunity; IGI Global: Bangkok, Thailand, 2007.

19. Roy, R. Sustainable product-service systems. Futures 2000, 32, 289-299. [CrossRef]

20. UNEP. Design for Sustainabilty D4S: A Step by Step Approach; UNEP: Nairobi, Kenya, 2009.

21. Manzini, E.; Vezzoli, C.; Clark, G. Product-service systems. Using an existing concept as a new approach to sustainability. J. Des. Res. 2001, 1, 27-40. [CrossRef] 
22. Manzini, E.; Vezzoli, C. Product Service Systems and Sustainability; United Nations Environment Programme: Paris, UK, 2002.

23. Tukker, A.; Tischner, U. Product-services as a research field: Past, present and future. Reflections from a decade of research. J. Clean. Prod. 2006, 14, 1552-1556. [CrossRef]

24. Firnkorn, J.; Müller, M. Selling mobility instead of cars: New business strategies of automakers and the impact on private vehicle holding. Bus. Strat. Environ. 2012, 21, 264-280. [CrossRef]

25. Baines, T.S.; Lightfoot, H.W.; Evans, S.; Neely, A.; Greenough, R.; Peppard, J.; Roy, R.; Shehab, E.; Braganza, A.; Tiwari, A.; et al. State-of-the-art in product-service systems. Proc. Inst. Mech. Eng. Part B J. Eng. Manuf. 2007, 221, 1543-1552. [CrossRef]

26. Hernandez, R.J. Designing Sustainable Product Service Systems: A Business Framework for SME Implementation. Ph.D. Thesis, Loughborough University, Loughborough, UK, November 2012.

27. Mont, O. Drivers and barriers for shifting towards more service-oriented businesses: Analysis of the PSS field and contributions from Sweden. J. Sustain. Product Des. 2002, 2, 89-103. [CrossRef]

28. Sutanto, A.; Yuliandra, B.; Tjahjono, B.; Hadiguna, R.A. Product-service system design concept development based on product and service integration. J. Des. Res. 2015, 13, 1-19. [CrossRef]

29. Maxwell, D.; van der Vorst, R. Developing sustainable products and services. J. Clean. Prod. 2003, 11, 883-895. [CrossRef]

30. Omann, I. A Multicriteria Tool for Evaluating the Impacts of Product Service Systems on Sustainable Development: An Application in Austrian Companies; SERI: Vienna, Austria, 2007; p. 5.

31. Creusen, M.E.H. Research Opportunities Related to Consumer Response to Product Design. J. Product Innov. Manag. 2011, 28, 405-408. [CrossRef]

32. Besch, K. Product-service systems for office furniture: Barriers and opportunities on the European market. J. Clean. Prod. 2005, 13, 1083-1094. [CrossRef]

33. Rexfelt, O.; Ornäs, V.H.A. Consumer acceptance of product-service systems. J. Manuf. Technol. Manag. 2009, 20, 674-699. [CrossRef]

34. Robson, C. Real World Research, 3rd ed.; Wiley: Chichester, UK, 2011.

35. Yin, R.K. Case Study Research: Design and Methods; SAGE Publications: Thousand Oaks, CA, USA, 2009.

36. Gibbs, G. Analizing Qualitative Data; SAGE Publications: London, UK, 2007.

37. King, N. Template analysis. In Qualitative Methods and Analysis in Organizational Research; SAGE Publications: Thousand Oaks, CA, USA, 1998.

38. Hernandez-Pardo, R.J.; Bhamra, T.; Bhamra, R. Sustainable product service systems in Small and Medium Enterprises (SMEs): Opportunities in the leather manufacturing industry. Sustainability 2012, 4, 175-192. [CrossRef]

39. Hernandez, R.J.; Bhamra, T.; Bhamra, R. Exploring SME perceptions of sustainable product service systems. IEEE Trans. Eng. Manag. 2013, 60, 483-495. [CrossRef]

40. Armstrong, C.M.; Niinimäki, K.; Kujala, S.; Karell, E.; Lang, C. Sustainable product-service systems for clothing: Exploring consumer perceptions of consumption alternatives in Finland. J. Clean. Prod. 2015, 97, 30-39. [CrossRef]

41. Moreno, M.; de los Rios, C.; Rowe, Z.; Charnley, F. A conceptual framework for circular design. Sustainability 2016, 8, 937. [CrossRef]

42. Enkvist, P.-A.; Klevnas, P. The Circular Economy. A Powerful Force for Climate Mitigation: Transformative Innovation for Prosperous and Low Carbon Industry; Material Economics Sverige AB: Stockholm, Sweden, 2018.

43. Sinclair, M.; Sheldrick, L.; Moreno, M.; Dewberry, E. Consumer intervention mapping-A tool for designing future product strategies within circular product service systems. Sustainability 2018, 10, 2088. [CrossRef]

(C) 2019 by the author. Licensee MDPI, Basel, Switzerland. This article is an open access article distributed under the terms and conditions of the Creative Commons Attribution (CC BY) license (http://creativecommons.org/licenses/by/4.0/). 